\title{
Decision Premises, Learning and Organizational Resilience Addressing Novel Adversities
}

\section{Maria Laura Frigotto, Loris Gaio, Alessandro Narduzzo, and Marco Zamarian}

\section{INTRODUCTION}

Organizational resilience refers to the ability to bounce back, respond and recover when facing disturbances (Linnenluecke, 2017) or adverse

M. L. Frigotto · L. Gaio · M. Zamarian

Department of Economics and Management, University of Trento, Trento, Italy e-mail: marialaura.frigotto@unitn.it

L. Gaio

e-mail: loris.gaio@unitn.it

M. Zamarian

e-mail: marco.zamarian@unitn.it

A. Narduzzo $(\bowtie)$

Faculty of Economics and Management, Free University of Bozen-Bolzano, Bolzano, Italy

e-mail: anarduzzo@unibz.it

(C) The Author(s) 2022

R. Pinheiro et al. (eds.), Towards Resilient Organizations and Societies, Public Sector Organizations, https://doi.org/10.1007/978-3-030-82072-5_2 
triggers (Fisher et al., 2018). Resilience addresses both exceptional and devastating events, as well as a larger set of disruptions and disturbances that in various ways do not match with those occurrences that 'the system is designed to handle' (Boin et al., 2010, p. 8). Wildavsky (1988) added a relevant distinction between adversities that can be foreseen (and that belong to the area of 'anticipation') and those that consist of unknown challenges that are unanticipated before they become manifest (that map into the area of resilience). As such, novelty is a grounding condition of disturbances or adverse triggers (Frigotto, 2020). Novelty can assume different degrees up to an extreme at which it consists of something that is not deemed possible. This range implies that organizations need to prepare themselves to face what is so unknown that it is not thought of (Frigotto, 2018).

From this perspective, resilience consists of the ability to detect the novelty that can be triggering adversities; as such, it is an ability that is essentially undetermined and ill-defined, as Perrow (1999) and Wildavsky (1988) revealed. Weick developed this conceptualization further by reframing adversities as 'the unexpected', namely, in terms of what is not expected and not thought, given the present approach to giving sense to the world known as 'sensemaking' (Weick, 1993; Weick \& Roberts, 1993; Weick \& Sutcliffe, 2001). Through this lens, resilience is also 'less deterministic' (Linnenluecke, 2017, p. 8) and highly dependent on the moment and the context in which resilience is enacted. The inclusion of novelty into resilience requires organizations to acquire a mindset that deems the unthinkable possible and to structure themselves into specific roles, procedures and units that support this mindset coherently with the posture of 'expecting the unexpected' postulated by Weick and Sutcliffe's contribution in 2001 .

In addition, in the field of crisis management, the two prevailing approaches to increase the ability to deal with emergencies are the planning and analysis of contingencies (Boin \& McConnell, 2007; Levac et al., 2012). Both approaches try to increase organizational resilience by preparing the management systems to deal with known and recurrent crises; nevertheless, they are substantially ineffective when organizational resilience depends on the ability to cope with novel and unexpected adversities and consists of learning capabilities (Lalonde, 2007).

In this chapter, we illustrate and theorize the difficulties that novel and unexpected emergencies pose to organizations and that make them actually struggle to be resilient. We build on the framework outlined by 
Simon (1991) to explain how organizations learn to deal with novel problems; this framework dates back to Simon and Newell (1971). In this framework, decision premises affect the representation of the problem and, ultimately, the possibility to detect, interpret and respond to novel situations. From this perspective, the ability to revise the initial decision premises, i.e., to expand the perceptual limits of observation and to conceive a novel representation of the problem, provides the foundation of the ability to detect unknown situations and, ultimately, to be resilient in the face of novelty in adversities.

We theorize organizational resilience as pertaining to the ability to revise decision premises in the face of novel and unexpected adversities by combining the resilience literature with Simon's contribution. We develop this conceptualization into a set of structural elements that can be adopted by organizations to build resilience. First is a mindset that contemplates the unknown among the possible situations to be faced and stimulates the revision of decision premises. Second, the organizational role of the 'Challenger of Decision Premises' (CDP) is deliberately designed to challenge the existing decision premises to consider novelty that might not be apparent.

In the next section, we report the real case of a fire emergency that occurred in Italy in 1993.

We introduce this case in the front end of our chapter with an illustrative purpose (as in the tradition of, for instance, Weick, 1993) to display the specific issues that novel and unexpected emergencies pose to organizations and their attempts to be resilient. Third, we build on Herbert Simon's learning theory on the solution of new problems, adapting it to the context of emergency management to provide our theoretical framework of resilience in the face of novelty adversities. In the fourth section, we develop the role of the 'Challenger of Decision Premises'. Finally, after having outlined the theoretical perspective building our model, in the last section, the case of the fire illustrated in section two is recalled with explicit reference to the proposed theoretical framework.

The chapter concludes by arguing that organizations can prepare and be more resilient in dealing with new emergencies. In this case, preparedness means learning to revise the decision premises and develop a new appropriate representation of the situation while the novel emergency is being addressed. 


\section{Fighting an Everlasting Fire}

This section presents the narrative of a firefighting intervention operated by a brigade in Northern Italy as an illustration of the issues that the unexpected raises in the ability of organizations to detect and respond to adversities. This incident was disclosed by the Fire Chief and the Deputy Chief of the Fire Department that operated the intervention, in the context of an open interview that occurred in 2015. The interview was contextualized in a larger research project aimed at grounding, in the empirical experience of nearly 40 years of firefighting activity, what novelty consists of in the context of emergency management. The following narrative reports a case in which novelty is presented in context, providing the background for our theoretical elaboration. In the last section, the case will be revisited and related to the theoretical contribution developed throughout the chapter.

One evening in November 1993, a fire broke out in an industrial plant producing frozen meals in Bolzano, Italy. It was a long and complicated intervention, lasting 11 hours. After 7 hours, the fire was still spreading; the high heat produced structural damage to the building, hampering firemen operating in the face of over 360 degrees Celsius for a long time. However, we are not retelling it in this context for the exceptional risk it produced but because this case illustrates the essence of the unexpected in the view of the professional firefighters involved, i.e., the difficulty in understanding and making sense of the situation.

In this intervention, a brigade of 10 firemen was sent out; the Fire Chief (FC) acted as incident commander, ${ }^{1}$ and his Deputy as senior Officer (DC). Since the fire was large, other firemen were recalled from off-duty. It was already dark when they started to fight the fire, and a very dark and intensifying smoke hampered the detection of fire and the ability to tackle it directly. Therefore, they first started to fight the fire from outside; then, as is routine in these cases, the fire squad opened the windows and started fans to remove the smoke and identify the origin of the fire. They located the core of the fire and attacked it from both the inside and the outside. However, when they thought they had tamed the fire, the unexpected occurred:

${ }^{1}$ The "incident commander" is the person in charge of the solution of the emergency. The role is specifically important for large emergencies involving several organizations, as this person is in charge of coordinating the efforts. 
FC: "At one time, and I remember that perfectly well, this fire was more or less clear where it was; then suddenly another one started, in a different place. Later, a second outbreak and then a third, somewhere else. Then, while operations were in progress, a further outbreak was reported in the basement, where we had just passed."

At this point, the officers started re-analysing the situation, but the understanding they had built up to that moment and that had led them to attack the fire showed several discrepancies:

FC: "I must say that I was very confused, I remember, very confused, because the first outbreak could actually be there, I explained it to myself. The second one was already a bit anomalous, but it could be related in some way to the first. But the new outbreak, after three quarters of an hour of intervention, two floors below the first fire? that was really strange."

In addition, a new outbreak has been reported in the basement, where the incident commander just passed by; that piece of evidence did not fit a logical explanation of how these new fires could have started:

FC: "It was strange because we in the basement had seen three bags of potato starch used to prepare the gnocchi that were soaking wet because the water from the pipes had leaked from the second-floor walls to the basement. We had walked in the pulp of wet starch, doing: splosh-splosh. [...] In short, the situation was no longer correct.

DC: "At least at first analysis, there was no logical correlation between the first fire and the following ones."

In this situation, they started exploring all the possible explanations:

FC: "So, when you hear that down in the basement it burns again, you ask yourself, how is that possible? How can it be? [...] In short, one evaluates several hypotheses to give a reason to what is happening."

DC: "At first, I [...] had assumed that there was a channel connecting the second floor with the basement, and that something had fallen down that burned. For example, an elevator or a conduit." 
However, their assessment was made difficult due to the lack of information. For example, in this case, maps of the building were not provided.

A large part of this analysing activity was performed in teams, at the Incident Command Post, a temporary direction unit that is established near the site to coordinate operations. Information on operations converges to this post, where commanders reason on why each action is performed and thus update their picture of the situation.

FC: "The scene is put together one piece after the other. And then you start discussing; 'But what can it be?' You try to integrate the current understanding with additional information [...]. For example, it is possible that someone in the crew already knows the building for having made inspections for fire prevention. All this information is then shared."

During this discussion, all the details were assessed, and the multiplicity of observers was exploited. In this case, while it is normal that workers and managers of the factory remain around the building or even inside in the areas that are not on fire, both FC and DC noticed that they had met a man several times during their inspections.

FC: "I may be confused, I may have been in the wrong direction, but there were two of us and we both noticed the presence of this person."

They set a context to validate the hypothesis that that man could be an arsonist. They asked the police to hold him for an identity check; thus, had they not observed any new outbreaks in the meantime, this holding would have supported the arsonist hypothesis. The hypothesis was validated and, in fact, it later came out that the man was a former employee that had been fired shortly earlier. Therefore, it was understood that there was someone who was setting the fire in new places while their intervention was in progress.

\section{The Challenge of New Emergencies}

Organizations coping with novelty may increase their resilience in essentially two ways. First, they can react to novel emergencies as they happen 
by adapting their response to the needs imposed by the new situation (that is part of a processual resilience); second, they can work before the emergency occurs, trying to enlarge the solutions to all the plausible novel emergencies they can think of (that is part of the ex-ante elaborated resilience-promoting factors) (Fisher et al., 2018). Emergency management systems can apply both of these solutions, also in combination. However, the latter approach has been well developed by both scholars and practitioners, unfolding under the themes of 'anticipation' (Wildavsky, 1988) and 'preparedness' (Hémond \& Robert, 2012; Perry et al., 2001). Likewise, the issue concerning how to support and to design an organization that is able to detect and respond to novel and unexpected emergencies is still an open question in both the literature and from practitioners' perspective. In particular, in the literature on resilience, there are studies that conceive of resilience as an ongoing activity that takes place together with the unfolding of events (Frigotto, 2020; also see first chapter of this book), some of them linking resilience to mindfulness, i.e., the ability to sustain awareness of the present moment (Frigotto \& Zamarian, 2015). These studies underline that processes and structures in organizations devoted to building reflection and designed to diversify perspectives help enhance resilience. They explain how organizations can continuously support resilience while standard operations are being performed by means of maintaining structures that are focused on different domains or by supporting reflection on the existing procedures while supporting experimentation and tolerating error.

In other words, they recognize that organizations need to combine what March (1991, p. 71) defines as 'exploration' and 'exploitation', intended respectively as pointing at 'search, variation, risk taking, experimentation, play, flexibility, discovery, innovation' or at 'refinement, choice, production, efficiency, selection, implementation, execution'. The extant literature elaborates on how to combine exploration and exploitation within the same organization (e.g., O'Reilly \& Tushman, 2013 on ambidexterity). However, it does not explain with sufficient depth, at a more micro level, how these activities are combined in the decision-making behaviour of the same individual and within the same organizational team.

Our idea of organizations learning from novel emergencies as they happen draws on Simon's (1991) theory of learning. Simon conceives of decision-making as an inferential process based on premises derived from norms and goals (Cohen, 2007). Problem solvers rely on norms, beliefs 
and goals that are taken for granted. However, solving new problems implies violating existing norms or reconsidering predefined goals.

This formulation seems particularly appropriate to analyse problemsolving in crisis management. In fact, Roberts and Wernstedt (2018) observe that emergency management systems consider how to choose between available alternatives without explicitly taking into account values and norms that constrain those decisions or to what extent the decision process consists of automatic actions. Similarly, Simon's framework on solving new problems acknowledges the importance of these premises (Simon, 1957, 1991).

In the field of emergency management, the concept of decision premises has been used to explain how stable structures, such as disaster management systems, can react in a flexible approach to facing unexpected events (Grothe-Hammer \& Berthod, 2017), such as sudden and large inflows of refugees (Meyer \& Simpsa, 2018). An account of failures in dealing with unexpected crises as reported by Page et al. (2006) while investigating the Hurricane Katrina incident notes that decision premises are often deformed by several factors: (a) former commitments to past choices, (b) negative information avoidance and defence of prior choices, (c) delusion of control over uncontrollable events and (d) wishful thinking.

To understand the challenges that new emergencies pose to emergency management organizations ${ }^{2}$ and to analyse what specific issues they pose in terms of resilience, this chapter takes a problem-solving perspective (Dynes, 1994; Simon, 1957, 1991) and conceives new emergencies as new problems to solve. Unfortunately, problems setting is itself a problematic issue, and identification and definition may not necessarily result in a classification task. In real situations, the available information (i.e., contradictory, partial, and unreliable, etc.) and the evolving conditions make it more difficult for the decision-makers to understand whether the ambiguous and unclear situation is familiar or novel.

Therefore, decision-makers perceive unclear and ambiguous stimuli that make them confront three possible alternatives: inaction, routinized response, or original solution (Billings et al., 1980). Inaction means that the organization does not react, because nothing has been detected and

2 In this chapter, we refer to emergency management organizations to indicate a class of high-reliability organizations (Weick \& Sutcliffe, 2001), that is, organizations that operate in complex and high-risk environments and still perform effectively and make few mistakes. 
therefore an emergency is not even perceived. Routinized response is the familiar response that the organization executes when the situation is perceived as familiar. Finally, an original solution is triggered when the organization detects that the situation is different from usual ones and that it requires a new problem formulation. Hence, solving new problems and learning from novel situations needs three major conditions to occur. First, the organization has to be able to perceive that the situation at hand is different from the usual ones. Second, the organization has to be able to react by adapting its response to the situation. Third, to be resilient, the organization needs to react and respond in a timeframe consistent with the survival of the system. To accomplish the first steps, problem solvers need to develop a problem representation, a process that is analysed in the next section.

\section{Acquiring New Problem Representations}

According to Simon and Newell (1971), problem solvers usually do not have full knowledge of the environment they operate in; therefore, they normally create a representation of the problem. To do so, problem solvers tend to use a base of knowledge they already retain in their various memories; they can rely on pre-acquired knowledge of the task environment they are operating in and on their own past experience with similar tasks and with components of the whole task they are facing. Additional sources of information are programmes (i.e., standard operating procedures) and more abstract pieces of knowledge that do not pertain to a specific situation but that are nevertheless considered relevant. For instance, when confronting a novel emergency that may affect an undefined number of people, an emergency management system that is still trying to identify the causes may adopt standard procedures to mitigate the negative effects of the hazard (Simon, 1991). A further source of knowledge that problem solvers can use is simulations, which can help generate hypothetical or counterfactual thinking.

If problem solvers are not able to gather any relevant information, they can try to construct a representation of the problem in a more abstract form. For instance, a city emergency management team may not have prepared a plan for dealing with blackouts, but in the event of a blackout, the team can reason in abstract terms about the main consequences produced by a prolonged lack of electrical power and plan the 
response, the priorities and the actions to undertake to mitigate the effects of the crisis.

To conceptualize novel situations, building on Simon (1991), we need to define the conditions that allow the actors to create cognitive representations of new problems. One of the most problematic situations is faced when actors fail to perceive the novelty and thus treat what is different and new as something familiar. To avoid this failure, decision-makers need to construct a representation of the problem that does not exclusively derive from an existing corpus of knowledge; this condition can be achieved in two complementary ways: by focusing on new information or by acquiring new sources of information (Simon, 1991).

Normally, problem solvers approach a situation that looks familiar by means of the usual representation of the problem. This approach should indicate an appropriate solution. Nevertheless, when the problem is novel and different, the decision-makers may notice anomalies in how the situation is characterized or evolves. If the anomalies persist, decision-makers start doubting the current representation of the problem. To define a novel problem representation, the decision-makers need to reconsider the decision premises, which are composed of the following: beliefs; organizational arrangements (such as roles); communication channels; and, more generally, pieces of knowledge that are taken for granted when decisions are made. Following Simon (1991), we contend that decision premises are a fundamental element in this respect, as decision-making consists of a process of inference.

According to Cohen (2007), decision premises should be studied as a unit of analysis to understand organizational behaviour at large. For instance, authority can be framed as the acceptance of premises set by hierarchical superiors. Similarly, trust can be defined as the acceptance of premises by others without further inquiry.

Given the importance of decision premises in building a new representation of the problem, it is necessary to understand how the decision premises are formed. In organizational settings, communication is extremely important with respect to the formation of decision premises in at least two ways. First, decision premises are shared within the organization through communication channels. Second, communication responsibility and communication channels are also elements forming the decision premises; what makes legitimate the communication and its content is also subject to decision premises. Therefore, any solution 
that organizations may consider to revise the decision premises should incorporate communication.

According to Simon (1991), to elaborate a problem representation that is useful to deal with novel problems, problem solvers have two complementary options. First, they can learn how to use an existing problem representation and to explore its limits. For instance, problem solvers may allocate some attention to assessing to what extent this representation is coherent with pieces of evidence of the current situation. This effort exposes the decision-makers to the usual two types of errors. A type 2 error (false negative) exists when our representation fails to acknowledge actual states of the problem; a type 1 error (false positive) exists when the representation considers states of the problem that do not exist. In other words, the first option consists of assessing to what extent the representation of the problem is still useful to understand the situation. The second option consists of creating a new representation for the novel problem. Nevertheless, creating a new problem representation is only the first step that organizations can undertake. The next is to enable organization members to learn how to use the new problem representation.

How Simon (1991) describes the process through which problem solvers approach a novel situation guided by decision premises can be reformulated in cognitive terms as a sensemaking effort (Weick, 1995), that is, an attempt to make sense of something that is not immediately and clearly understood. Weick (1995, p. 4) agrees that sensemaking involves 'placing stimuli into some kind of framework' that is provided, in Simonian terms, by the decision premises. In fact, decision premises define the boundaries and context for the processes of cue noticing, filtering and classifying that are essential elements of sensemaking. Trying to capture the complexity of sensemaking in a synthetic image, Weick (2001) links sensemaking to cartography and to the effort of orienting within a situation that seems to be underdefined, unclear or equivocal. Along with this image, we observe that Simon's decision premises provide the initial coordination system that problem solvers adopt to orient themselves when facing a novel situation.

An additional and convincing bridge connecting, problem-solving perspective and sensemaking is provided by Schön (1983, p. 40), who observes that 'problems do not present themselves to the practitioners as givens. They must be constructed from the materials of problematic situations which are puzzling, troubling, and uncertain. To convert a problematic situation to a problem, a practitioner must do a certain 
kind of work. He must make sense of an uncertain situation that initially makes no sense'. In Simon's (1991) language, decision premises serve as building blocks to do that kind of work.

What we have thus far outlined to explain how organizations approach novel problems by acquiring and developing appropriate problem representations is not limited to a cognitive dimension but rather involves precise and observable patterns of behaviour that Simon associates with the idea of organizational roles.

\section{The Structure of Roles}

According to Simon (1991), organizational roles depict the role embodied by single individuals in organizations or defined by a set of tasks. 'Roles tell organization members how to reason about the problems and decisions that face them: where to look for appropriate and legitimate informational premises and goal (evaluative) premises, and what techniques to use in processing these premises' (Simon, 1991, pp. 126-127). From this perspective, roles are not systems of 'prescribed behaviours', as they are typically considered but are rather systems of 'accepted decision premises'. Roles instruct people on how to reason about the representation of the problem and the decisions - where to look for appropriate and legitimate informational and goal premises and what techniques to use in legitimating these premises.

Roles imply responsibilities, division of labour and coordination mechanisms that regulate organizational behaviour. They can be general in nature and persistent across time and organization. For instance, in business firms, some roles, such as selling, production, and accounting, etc., historically tend to always be present and are defined in functional terms.

In the field of emergency management systems, crisis management has been traditionally conceptualized by decomposing the overall problem into four interrelated subproblems: preparedness, mitigation, response and recovery. This cognitive representation of the management of crises provides the scaffolding to create distinct roles and decision premises in each of these four elements.

In some cases, such as in military or military-like organizations, roles are formally and explicitly defined hierarchically. Alternatively, roles can emerge by imitation from other organizations that are taken as models. For instance, a well-known role system in emergency management, such as the Incident Command System (ICS) developed in the USA in the 
1970s, has been subsequently adopted by other countries and eventually became an international standard (York \& MacAlister, 2015).

As a further example, firms that build their competitive advantage on safety, efficiency and/or customer satisfaction underpin differentiated roles that eventually contribute to generate that distinctiveness (Simon, 1991). Roles are connected to specialization and to the development of domain-specific knowledge that is coherent with the goals of the firm. Consistent with this line of thought, we can also assume that organizations may create new roles to redefine their goals.

\section{The Role of Challenger of Decision Premises}

Among the new roles that existing organizations can adopt, we are interested in roles that increase the organizational ability to perceive, react and learn how to cope with novel problems deriving in particular from new and unexpected emergencies. From the perspective of Simon's (1991) decision premises, novelty requires emergency management organizations to redefine the decision premises they use to make sense of the world (Weick, 1995). This approach implies, first, acknowledging the idea that not all possible emergencies are already known, even though the organization has already acquired a considerable amount of knowledge through previous experience, and that the problem representation that was built by relying on that knowledge is not always useful. A second implication for emergency management organizations concerns how they can prepare for novel emergencies. In fact, a resilient response to novelty is not attained by preparing the organization response in advance, given that the emergency is not known in advance and cannot be anticipated. Instead, the response has to be elaborated during the setback. As decision premises are discussed and reconstructed in relation to novelty, the actions and the states of response and recovery are learned throughout the crisis. However, this learning does not imply that nothing can be done before the crisis. In contrast, the elaboration and exercise of a repertoire of standard responses provides the necessary ingredients for further combination and ex novo generation of responses when novelty is faced. In addition, preparation can consist of training the ability to challenge decision premises, as they are typically taken for granted (Frigotto, 2018).

Under such revised decision premises, emergency detection ceases to be a simple task of classification, where the decision-makers use contextual information to identify which type of crisis they are facing. In contrast, 
it becomes a task that concerns the acquisition of continuous awareness on the decision premises that underpin organizations' decisions and operations. Nevertheless, decision-makers may not be able to assess that novelty is implied in the current situation; they may perceive the situation as implausible or unthinkable and therefore out of the spectrum of possibilities. Alternatively, they eventually may not perceive it at all. In other words, once new and unexpected emergencies are deemed possible, then the emergency recognition cannot be simply reduced to technical rationality and requires the ability to scrutinize and make sense of weak, contradictory and evolving cues (Weick, 1995). Not only the situation itself may appear novel to the decision-makers but also their own actions may produce unintended consequences.

Because of these reasons, to increase resilience in facing novel and unexpected crises, organizations may introduce a dedicated role in charge of challenging decision premises that is responsible for continuously doubting the conventional representation of the situation while it unfolds.

We represent this role in Fig. 2.1. Consistent with Simon's (1991) perspective, we modelled this role within a role system that results from a division of labour aimed at letting individuals specialize in specific areas. Each role features a set of accepted decision premises coherent with the

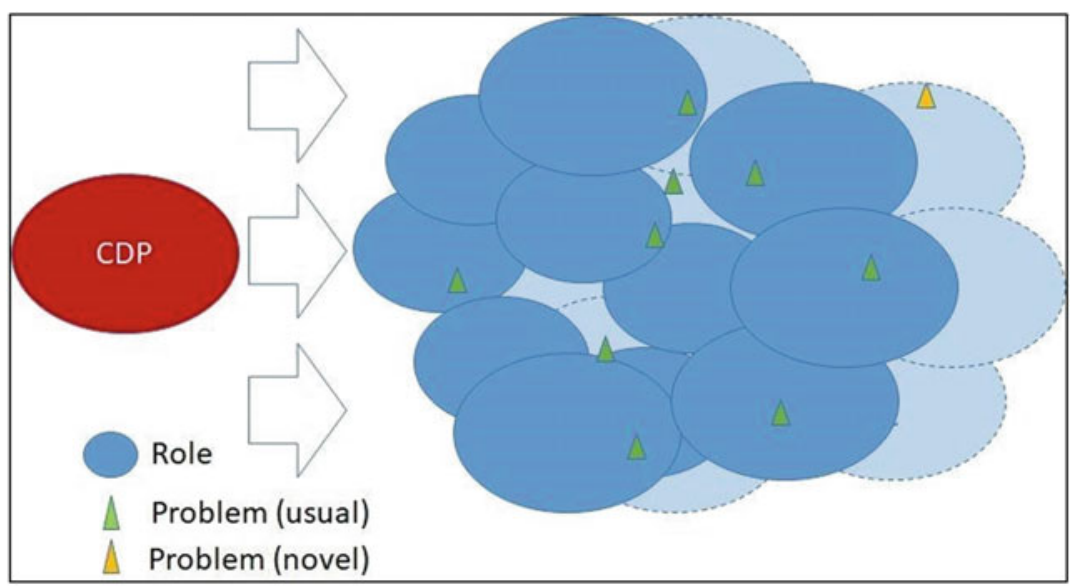

Fig. 2.1 The challenger of decision premises as a role (Source Authors own elaboration) 
need to monitor and explore a specific subset of problems. Decision premises are 'sticky' and partly define each role and, consequently, the expectations that others have of the actions of the person occupying that role. Therefore, all else equal, we cannot expect roles to evolve significantly on their own. The process of challenging the decision premises, then, is paramount for the ability of the organization to face novel situations, as a novel situation, by definition, is a situation that falls outside the scope of the existing decision premises.

Coherently with this Simonian approach, decision premises are legitimized through a learning process. Each role, as we noted above, encompasses a set of decision premises that are considered legitimate as long as they allow the decision-maker to produce outcomes that are coherent with the design of the role he/she was assigned and, in turn, as long as the role thus played is coherent with organizational goals. The legitimacy of discrete, individual actions is thus mainly a matter of conformity. The ability to face novelty at the organizational level is clearly outside the scope of these actions. Suchman (1995), examining the strategies that organizations employ for maintaining legitimacy, underscores the need to exert bridging efforts that can encompass logics that are different from the ones currently prevailing within the organization/role. One significant example of bridging effort of this kind is the so-called 'doubting Thomases' that have the explicit mandate to question others' taken-for-granted assumptions (Ashforth \& Gibbs, 1990). In Fig. 2.1, for the sake of clarity, we represent the process of challenging decision processes as pertaining to a new role (i.e., Challenger of the decision premises, or CDP).

An explicit mandate, however, does not translate automatically in the needed level of legitimacy to act in this fashion. March and Simon (1958) clarify that problem-solving activities can happen because of a process that they call 'recognition'. In this cognitive process, problem-solving actions and problem situations are matched. This process appears obvious for standard roles stemming from division of labour, however, understanding why it can be applied to a role characterized as being devoted to discussing accepted decision premises requires a further step. In fact, we are talking about a role that aims (as a rule) to apply the recognition process to situations that are (or could be) novel. In fact, we claim that the process of challenging decision premises can work under the logic of recognition in two distinct cases. The first such case is when an event, or a series of events, had dire consequences for the survival of the organization 
and the organization itself only admitted a standard problem-solving logic based on division of labour, roles with sticky decision premises and the exante conviction that all relevant contingencies had been taken care of. In case of failure, it is reasonable to believe that the organization would not only revise the decision premises of each role, or even redesign its system of roles, but also integrate a different logic in decision-making. A second case is the case of organizations facing such an unforgiving environment that constantly discussing the decision premises regulating its problemsolving processes represents a basic strategy to face the risk of annihilation. Further, we should observe that only relying on the principle that a person embodying this role needs to be recognized as an authoritative source of knowledge and competence would entail an inherent element of frailty for the organization.

From this perspective, reasoning about a problem essentially means ascertaining a) where to look for appropriate and legitimate decision premises and $b$ ) how to process these premises; what other and apparently unrelated contexts may provide alternative decision premises that seem appropriate? Under different premises, what boundaries of the problems, previously unforeseen, become evident? What new states are unveiled? What future consequences can be inferred? What new domains of expertise gain a critical importance in identifying a solution? Filling this role implies a legitimate challenge to the explanations of the situation that seems to fit most of the evidence and thus urges consideration of new information premises that are otherwise underweighted or missing and the processing of these premises to construct novel representations. To reach this goal, we propose to introduce a new role, associated with the following specific duties: setting novel and different decision premises that provide the grounds of assumption upon which rest formulating and endorsing problem solutions that would otherwise be rejected, as they are not compatible with the conventional beliefs.

Whoever exerts this role has the responsibility to question the accepted decision and goal premises that provide the grounds for any decisionmaking. In addition, this role implies the ability to develop a new representation of the problem and to use it for the decision to be made. Consequently, problem-solving is not conceived of as a linear sequence of phases but rather as an iterative and circular process, where premises are constantly being questioned as well as the co-evolution of premises, problems and solutions. 
In addition, the role also implies enabling organizational members to learn how to use the new representation of a novel problem. In terms of organizational learning, this role entails two complementary processes: connecting new information and knowledge first to the existing culture and second to the existing role system. This process can be hard to undertake when organizations assume that, because of their expertise, everything is already known, and further explorations of the problem may unveil some inconsistencies in the problem representation.

Emergency management organizations can quickly react to critical events by executing complex responses involving various organizations or subunits; nevertheless, this expertise requires relying on a shared and consistent problem representation that may be endangered by new representations.

\section{A Theoretical Perspective on the Everlasting Fire}

Conceptualizing organizational resilience as a process of learning to solve novel and unexpected problems led us to consider the combination of decision premises, problem representations and role systems, as proposed by Simon (1991), to explain the organizational capability of dynamically solving new problems. In many instances, resilience is portrayed as the ability of an existing structure of roles to be robust in the face of adversity (Linnenluecke, 2017). In our approach, in contrast, resilience consists of the ability to change by means of learning to scrutinize and challenge the current system of decision premises. To acquire this form of resilience, organizations may deliberately introduce and support the CDP role described above.

The case presented at the beginning of this chapter (second Section) concerned an emergency management organization facing a novel emergency that lies outside the realm of organizational decision premises. After having outlined the theoretical framework, the case is commented below, and further theoretical development is provided.

At first, the emergency resembled a normal fire; nothing was disconcerting or unexpected. Nevertheless, during the operations, firefighters began to notice some discrepancies between what they observed and what they expected. These discrepancies were initially explained according to the usual decision premises. Confronted with the first anomaly, actors thought that they had not seen the fire when they had gone through the basement because of the dense smoke. Confronted with the second 
anomaly, firefighters thought that fire does not spread from top to bottom. However, from previous experiences, they knew that such a spread could happen through conduits; often, these conduits are not visible. Confronted with the third oddity, that a person was repeatedly seen walking inside the building, firefighters guessed that this was perhaps an employee, as often happens in plants; they also considered the possibility that, because of the smoke, the person in question was not always the same. In terms of sensemaking, the discrepancies triggered a need for explanation (Weick, 1995), which is initially found within the space of the possibilities consistent with the assumed premises. In terms of a trade-off between exploration and exploitation (March, 1991), at the beginning, the problem solvers try to explain the situation by relying on the decision premises and, therefore, by exploiting a consolidated problem representation. Since the discrepancies persist, problem solvers also explore alternative possibilities not backed up by assumed premises. In other words, what we observe is an ambidextrous response, consisting of both exploitation and exploration, that enriches the organizational response and, ultimately, its resilience.

The fundamental discrepancy that forced firefighters to question their representation of the problem was timing; after many hours, the fire had not yet been tamed. The longer the fire lasted, the more relevant the discrepancy appeared. Eventually, all the discrepancies were account by, but to make sense of them and to formulate the hypothesis that the arsonist was still around to light additional fires, firefighters needed to reconsider their problem representation by including a possible state that was not initially conceived. In fact, arsons were certainly included into the problem representation conceived by an experienced fire brigade; nevertheless, the accepted decision premises considered the model of an arsonist that lights the fire and then flees the scene. In this case, the fire flared up in a way that was considered inconsistent until the firemen formulated an alternative (novel) hypothesis that contrasted with the accepted decision premises and acted to test the former.

In devising the hypothesis that the arsonist was still lighting fires, the Fire Chief and his Deputy played the role of the CDP. As a matter of fact, they tried to think beyond the consolidated problem representation and learned to solve the novel emergency while it was unfolding. Moreover, while they noticed the discrepancies, they also started challenging their own decision premises. They considered a novel representation of the problem and used that representation to conceive and execute an action 
(i.e., asking the police to stop the suspect with an excuse) that could allow them to learn whether their hypothesis was supported by additional evidence. The cycle of sensemaking is then complete (Weick, 1995); the surprise generated by the discrepancies moves beyond the need for explanation and, instead, triggers a sequence of actions that eventually produce a revision of the decision premises.

This case suggests further reflections on the role of the CDP that we outlined to increase organizational resilience in dealing with novel and unexpected emergencies.

First, thinking out of the box implies questioning the current system of knowledge, that is, decision premises and accepted representations of the problem. Legitimacy is a critical aspect of this process and of the CDP role. Not surprisingly, in this emergency, the role was filled by experienced officers at the top of the hierarchy. Nevertheless, we wish to emphasize that these conditions are not necessary requirements to fill the role, provided that the CDP role is legitimated by the hierarchy. Second, challenging the decision premises is not the only main task of the CDP; this role implies that organizations learn and use new problem representations constructed on revised decision premises and behave accordingly. To reach this collective achievement, the CDP may rely on organizational communication.

\section{CONCLUSIONS}

In this chapter, we conceived of organizational resilience as the ability to perform the exploration of a new set of alternatives to solve novel problems when the exploitative application of the current set seems unexpectedly ineffective (March, 1991); at that point, discrepancies are noticed, and they may trigger a revision of the decision premises. Building on Simon (1991) and his insightful remarks on the importance of decision premises to guide organizational behaviour, we can anticipate and explain why organizations may face fundamental difficulties in integrating two distinct perspectives, such as proactiveness and reactiveness, in the context of conflicting decision premises. On the one hand, resilience is intrinsically a processual property and is connected to the unfolding of the events; on the other hand, what the organizations learn to increase their resilience in dealing with a novel crisis is a capability that will be available 'ex-ante' and that we associate with the introduction of a CDP within the role system. The case being explored contributes to a richer understanding 
of resilience when organizations are dealing with novel or unexpected crises. We argue that preparedness can enhance resilience, when and if it includes learning on how to solve new crises while they unfold. We defined a particular profile within the organizational role structure, the CDP, that may be decisive to identify solutions that initially were not even considered as they were not part of the representation of the problem.

By designing behaviours and roles that support the challenge and reformulation of decision premises and that can be learnt before novel and unexpected adversities take place, but also by leaving their processual deployment and specific content to the time slot when adversities hit, our chapter contributes to the understanding of resilience as a phenomenon that occurs and can be designed both in foresight and while adversities take place.

Acknowledgements Funding for this chapter was provided by the second Research Grant awarded by the Autonomous Province of Bozen-Bolzano as part of the specific research project on Recognizing and reacting to new emergencies: an organizational perspective (funding agreement $2 / 40.3,13.02 .2014$ ). We thank Guido Ferrari and Ernst Preyer for their help in reconstructing the case described in the chapter. Any mistake or inaccuracy is the sole responsibility of the authors.

\section{REFERENCES}

Ashforth, B. E., \& Gibbs, B. W. (1990). The double-edge of organizational legitimation. Organization Science, 1(2), 177-194.

Billings, R. S., Milburn, T. W., \& Schaalman, M. L. (1980). A model of crisis perception: A theoretical and empirical analysis. Administrative Science Quarterly, 25, 300-316.

Boin, A., Comfort, L. K., \& Demchak, C. C. (2010). The rise of resilience. In L. K. Comfort, A. Boin, \& C. C. Demchak (Eds.), Designing resilience: Preparing for extreme events (pp. 1-12). University of Pittsburgh Press.

Boin, A., \& McConnell, A. (2007). Preparing for critical infrastructure breakdowns: The limits of crisis management and the need for resilience. Journal of Contingencies and Crisis Management, 15(1), 50-59.

Cohen, M. D. (2007). Perspective-Administrative behavior: Laying the foundations for Cyert and March. Organization Science, 18(3), 503-506.

Dynes, R. R. (1994). Community emergency planning: False assumptions and inappropriate analogies, 1994. University of Delaware, Disaster Research Center Article, 275. 
Fisher, D. M., Ragsdale, J. M., \& Fisher, E. C. S. (2018). The importance of definitional and temporal issues in the study of resilience. Applied Psychology, advance online publication.

Frigotto, M. L. (2018). Understanding novelty in organizations: A research path across agency and consequences. Palgrave MacMillan.

Frigotto, M. L. (2020). Reframing resilience on novelty and change. In Handbook of organizational resilience (pp. 53-69). Edward Elgar Publishing.

Frigotto, M. L., \& Zamarian, M. (2015). Mindful by routine: Evidence from the Italian Air Force Tornado crews flying practices. Journal of Management of Organization, 21(3), 321-335.

Grothe-Hammer, M., \& Berthod, O. (2017). The programming of decisions for disaster and emergency response: A Luhmannian approach. Current Sociology, 65(5), 735-755.

Hémond, Y., \& Robert, B. (2012). Preparedness: The state of the art and future prospects. Disaster Prevention and Management: An International Journal, 21(4), 404-417.

Lalonde, C. (2007). Crisis management and organizational development: Towards the conception of a learning model in crisis management. Organization Development Journal, 25(1), 17-26.

Levac, J., Toal-Sullivan, D., \& O'Sullivan, T. L. (2012). Household emergency preparedness: A literature review. Journal of Community Health, 37, 725-733.

Linnenluecke, M. K. (2017). Resilience in business and management research: A review of influential publications and a research agenda. International Journal of Management Reviews, 19(1), 4-30.

March, J. G. (1991). Exploration and exploitation in organizational learning. Organization Science, 2(1), 71-87.

March, J. G., \& Simon, H. A. (1958). Organizations. Wiley.

Meyer, M., \& Simsa, R. (2018). Organizing the unexpected: How civil society organizations dealt with the refugee crisis. VOLUNTAS: International Journal of Voluntary and Nonprofit Organizations, 29(6), 1159-1175.

O'Reilly, C. A., III., \& Tushman, M. L. (2013). Organizational ambidexterity: Past, present, and future. Academy of Management Perspectives, 27(4), 324338.

Page, R. A., Jr., Tootoonchi, A., \& Rahman, S. (2006). Rational decision stages: The breakdown of rationality in strategic planning and implementation. Competition Forum, 4(1), 205-212.

Perrow, C. (1999). Organizing to reduce the vulnerabilities of complexity. Journal of Contingencies and Crisis Management, 7(3), 150-155.

Perry, R. W., Lindell, M. K., \& Tierney, K. J. (Eds.). (2001). Facing the unexpected: Disaster preparedness and response in the United States. Joseph Henry Press. 
Roberts, P. S., \& Wernstedt, K. (2018). Herbert Simon's forgotten legacy for improving decision processes. International Public Management Journal, 22(4), 591-616.

Schön, D. A. (1983). The reflective practitioner. Ashgate Publishing.

Simon, H. A. (1957). Administrative behavior (2nd ed.). Free Press.

Simon, H. A. (1991). Bounded rationality and organizational learning. Organization Science, 2(1), 125-134.

Simon, H. A., \& Newell, A. (1971). Human problem solving: The state of the theory in 1970. American Psychologist, 26(2), 145.

Suchman, M. (1995). Managing legitimacy: strategic and institutional approaches. Academy of Management Review, 20(3), 571-610.

Weick, K. E. (1993). The collapse of sensemaking in organizations: The Mann Gulch disaster. Administrative Science Quarterly, 38(4), 628-652.

Weick, K. E. (1995). Sensemaking in organizations (Vol. 3). Sage.

Weick, K. E., \& Roberts, K. H. (1993). Collective mind in organizations: Heedful interrelating on flight decks. Administrative Science Quarterly, 38(3), 357-381.

Weick, K. E., \& Sutcliffe, K. M. (2001). Managing the unexpected: Assuring high performance in an age of complexity. Jossey-Bass.

Wildavsky, A. B. (1988). Searching for safety. Transaction Books.

York, T. W., \& MacAlister, D. (2015). Hospital and healthcare security. Butterworth-Heinemann.

Open Access This chapter is licensed under the terms of the Creative Commons Attribution 4.0 International License (http://creativecommons.org/licenses/ by $/ 4.0 /)$, which permits use, sharing, adaptation, distribution and reproduction in any medium or format, as long as you give appropriate credit to the original author(s) and the source, provide a link to the Creative Commons license and indicate if changes were made.

The images or other third party material in this chapter are included in the chapter's Creative Commons license, unless indicated otherwise in a credit line to the material. If material is not included in the chapter's Creative Commons license and your intended use is not permitted by statutory regulation or exceeds the permitted use, you will need to obtain permission directly from the copyright holder.

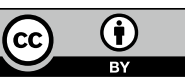

